\title{
Consumo, degradabilidade in situ e cinética ruminal em bovinos suplementados com diferentes proteinados
}

\author{
[Intake, degradability in situ and ruminal kinetics in cattle supplemented with \\ different protein supplements] \\ P.A.B. Miranda ${ }^{1}$, M.P.F. Fialho ${ }^{2}$, E.O.S. Saliba ${ }^{2 *}$, L.O.F. Oliveira $^{3}$, H.H.A. Costa ${ }^{1}$, \\ V.E.S. Lopes ${ }^{2}$, J.J. Silva ${ }^{4}$ \\ ${ }^{1}$ Empresa Brasileira de Pesquisa Agropecuária - EMBRAPA - Unidade Gado de Corte \\ ${ }^{2}$ Universidade Federal de Minas Gerais - UFMG - Belo Horizonte, MG \\ ${ }^{3}$ Empresa Brasileira de Pesquisa Agropecuária - EMBRAPA - Unidade Pantanal \\ ${ }^{4}$ Universidade Federal de Mato Grosso - UFMT - Cuiabá, MT
}

\begin{abstract}
RESUMO
Objetivou-se avaliar o efeito de combinações de diferentes fontes de nitrogênio não proteico com fontes de carboidratos como suplemento para bovinos sobre o consumo, degradabilidade in situ, taxa de passagem e cinética ruminal em bovinos. Os tratamentos consistiram nos seguintes suplementos proteinados: CSUENC = casca de soja + ureia encapsulada; CSUREIA = casca de soja + ureia; MTAMIR $=$ milho triturado + amireia; MTURENC $=$ milho triturado + ureia encapsulada, MTUREIA $=$ milho triturado + ureia. Os animais foram alimentados com feno de Brachiaria brizantha cv. Marandu como fonte de volumoso. O ensaio foi conduzido em delineamento quadrado latino $5 \times 5$ (cinco suplementos, cinco animais, cinco períodos). Não houve diferenças para consumo de nutrientes $(\mathrm{P}>0,05)$, exceto para consumo de proteína bruta $\mathrm{g} / \mathrm{kgPV}^{0,75}$, em que se verificou maior consumo no tratamento CSUENC. Para frações fibrosas, foram obtidas maiores ingestões de fibra em detergente neutro, fibra em detergente ácido $\left(\mathrm{kg} / \mathrm{dia} ; \% \mathrm{PV} ; \mathrm{g} / \mathrm{kgPV}^{0,75}\right)$, hemicelulose (\% PV; g/ $\mathrm{kgPV}^{0,75}$ ) quando alimentados com CSUREIA em relação àqueles com MTUREIA $(\mathrm{P}<0,05)$. Os tratamentos constituídos pelos diferentes proteinados não afetaram a degradabilidade in situ das frações nutricionais $(\mathrm{P}>0,05)$, exceto para fração potencialmente degradável da celulose. A concentração de nitrogênio amoniacal no líquido ruminal foi influenciada pela composição dos proteinados $(\mathrm{P}<0,05)$, sendo superior para os tratamentos MTUREIA e MTURENC em relação à CSURENC. As combinações entre diferentes fontes de nitrogênio não proteico e de carboidratos nos diferentes suplementos não modificam o consumo e a degradabilidade da forragem. Dessa forma, a escolha dos ingredientes para formulação de proteinados deve ser realizada considerando-se disponibilidade e preços desses suplementos.
\end{abstract}

Palavras-chave: digestibilidade in situ, taxa de passagem, suplementação proteica

\begin{abstract}
The aim of this study was to evaluate the effect of combinations of different sources of non-protein nitrogen with carbohydrate sources as supplement feed to cattle on intake, in situ degradability and passage rate. Treatments consisted of the following protein supplements: CSUENC $=$ soybean hulls + encapsulated urea $;$ CSUREIA $=$ soybean hulls + urea $;$ MTAMIR = ground corn + starea $;$ MTURENC $=$ ground corn + encapsulated urea; MTUREIA = ground corn + urea. The animals were fed with Brachiaria brizantha $\mathrm{cv}$. Marandu as roughage. The experiment was conducted in a latin square design (five supplements, five animals, five periods). The treatments did not affect the intake of nutrients $(P>0.05)$, although a higher intake of crude protein $\left(\mathrm{g} / \mathrm{kgBW} W^{0.75}\right)$ was observed by animals fed with CSUENC. A higher intake of NDF, ADF ( $\mathrm{kg} /$ day, $\left.\% B W ; \mathrm{g} / \mathrm{kgBW} \mathrm{W}^{0.75}\right)$ and hemicellulose (\% PV;
\end{abstract}

Recebido em 10 de junho de 2013

Aceito em 4 de agosto de 2014

*Autor para correspondência (corresponding author)

E-mail: saliba@vet.ufmg.br

Apoio financeiro: $\mathrm{CNPq}$ 
$g / \mathrm{kgBW}^{0.75}$ ) was observed by animals fed with CSUREIA when compared to those with MTUREIA $(P<0.05)$. The degradability of nutritional fractions was not affected by any of the treatments $(P>0.05)$, except for the potentially degradable cellulose. The ammoniacal nitrogen concentration in rumen fluid was influenced by the protein source $(P<0.05)$ and was higher for MTUREIA and MTURENC treatments in relation to CSURENC. The tested combinations of different sources of non-protein nitrogen with different carbohydrates did not affect the forage intake or degradability. Therefore, the choice of the ingredients for protein supplement formulation should be made considering other factors as availability and price of these supplements.

Keywords: digestibility, passage rate, protein supplement

\section{INTRODUÇÃO}

A pecuária brasileira, particularmente a bovinocultura de corte, em algumas regiões do Brasil, ainda é realizada em sistemas de criação extensivos. Dessa forma, níveis de desempenho satisfatórios na produção de carne podem não ser atingidos quando a forragem apresenta baixos teores de proteína bruta e de digestibilidade, fato que geralmente ocorre durante a estação seca na maior parte do Brasil tropical (Oliveira et al., 2010).

O fornecimento de suplementos proteicos tem sido intensamente utilizado nesse período nos sistemas de produção a pasto (Thiago, 1998), permitindo a manutenção da curva de crescimento de bovinos, diminuindo o tempo necessário para terminação. Suplementos formulados com fontes de proteína natural são usualmente caros. No entanto, a inclusão de compostos nitrogenados de origem não proteica possibilita redução de custos, uma vez que possui menor preço por unidade de equivalente proteico. Além de acrescentar nitrogênio $(\mathrm{N})$ em sistemas de produção com forragens de baixo valor nutricional, a adição de $\mathrm{N}$ não proteico (NNP) na suplementação mantém a concentração de amônia em níveis elevados, aumentando o consumo, em decorrência da melhoria na fermentação ruminal.

Algumas fontes de NNP, como amireia e ureia encapsulada, possuem taxa de liberação do $\mathrm{N}$ mais lenta, diferentemente da ureia que, por possuir alta solubilidade, apresenta taxa de degradação à amônia mais rápida, dificultando a utilização do $\mathrm{N}$ pelas bactérias ruminais (Tedeschi et al., 2002). Isso sugere que haja associação dos compostos que forneçam NNP com fontes de carboidratos que propiciem energia com semelhante taxa de degradação, implicando incremento na eficiência de utilização do $\mathrm{N}$ amoniacal pelos microrganismos, maximização da síntese de proteína microbiana, com consequente aumento das taxas de digestão e passagem, consumo de matéria seca e desempenho.

Dentre as fontes de carboidratos, o milho é utilizado como fonte de amido, sendo o principal componente energético dos concentrados. Além disso, quando utilizado de forma correta, pode melhorar as características de fermentação ruminal, principalmente pela maior eficiência da utilização de fontes de NNP, possibilitando uma melhor utilização dos carboidratos e maior fluxo de proteína microbiana para o intestino (Pereira et al., 2009).

Ao mesmo tempo, podem-se buscar estratégias de uso de fontes de carboidratos alternativas, como os resíduos oriundos da agroindústria, em que se destaca a casca de soja, que tem potencial uso, principalmente para ruminantes. A associação adequada dessas fontes de carboidratos com fontes de NNP pode potencializar o aproveitamento de forragens de baixa qualidade, principalmente no período das secas. Objetivou-se avaliar o efeito de combinações de diferentes fontes de nitrogênio não proteico (amireia, ureia e ureia encapsulada), associadas com fontes de carboidratos (milho e casca de soja), para formulação de suplementos proteinados para bovinos sobre o consumo, degradabilidade in situ e cinética ruminal em bovinos.

\section{MATERIAL E MÉTODOS}

O experimento foi conduzido na Fazenda Rancho Alegre, em Campo Grande, Mato Grosso do Sul, região típica de cerrado e campo limpo, 20 $0^{\circ} 13^{\prime}$ latitude sul, $54^{\circ} 35^{\prime}$ longitude oeste. A região possui clima do tipo tropical semiúmido, com registros de precipitação chuvosa de $116,2 \mathrm{~mm}$ no 
período experimental. Foram utilizados cinco bovinos Zebus, machos, com peso vivo médio de $721 \mathrm{~kg}$, dotados de cânula ruminal. Os animais foram alocados em baias individuais, com $16 \mathrm{~m}^{2}$, com bebedouros e cochos para alimentação. Os tratamentos foram constituídos de cinco suplementos: CSUENC = casca de soja + ureia encapsulada; CSUREIA = casca de soja + ureia; MTAMIR $=$ milho triturado + amireia; MTURENC $=$ milho triturado + ureia encapsulada; MTUREIA = milho triturado + ureia; (Tab. 1).

Tabela 1. Composição centesimal em matéria natural dos proteinados

\begin{tabular}{lccccc}
\hline \multirow{2}{*}{ Ingredientes } & \multicolumn{5}{c}{ Tratamentos } \\
\cline { 2 - 6 } Milho triturado & CSUENC & CSUREIA & MTAMIR & MTURENC & MTUREIA \\
Casca de soja & - & - & 26,7 & 40,0 & 36,5 \\
Farelo Soja & 47,5 & 47,5 & - & - & - \\
Ureia & 5,0 & 5,0 & 11,8 & 6,4 & 10,0 \\
Amireia & - & 9,5 & - & - & 9,5 \\
Ureia encapsulada & - & - & 20,0 & - & - \\
Fosfato Bicálcico 18\% & 9,5 & - & - & 10,0 & - \\
Carbonato Cálcio 35\% & 10,5 & 10,5 & 10,5 & 10,5 & 10,5 \\
Premipac Mult@ ${ }^{1}$ & 2,50 & 2,50 & 2,5 & 2,50 & 2,50 \\
Sal Branco & 6,00 & 6,00 & 6,0 & 6,00 & 6,00 \\
\hline
\end{tabular}

CSUENC $=$ Casca de soja + ureia encapsulada; CSUREIA $=$ Casca de soja + ureia; MTAMIR $=$ Milho triturado + amireia; MTURENC $=$ Milho triturado + ureia encapsulada; MTUREIA $=$ Milho triturado + ureia. ${ }^{1}$ Premipac Mult ${ }^{\circledR}$ : Níveis de garantia por kg do produto: Enxofre $=165 \mathrm{~g}$; Magnésio $=120 \mathrm{~g}$; Zinco $=28000 \mathrm{mg}$; Manganês $=9600 \mathrm{mg}$; Ferro $=11000 \mathrm{mg}$; Cobalto $=1000 \mathrm{mg} ;$ Iodo $=800 \mathrm{mg} ;$ Cobre $=12500 \mathrm{mg} ;$ Selênio $=125 \mathrm{mg}$.

Os animais receberam feno de Brachiaria brizantha cv. Marandu como fonte de volumoso em duas refeições diárias, permitindo-se sobras de $10 \%$. O período de adaptação dos animais ao feno foi de 20 dias. Foram fornecidos 600g/animal/dia dos suplementos proteinados pela manhã. $\mathrm{O}$ ensaio foi conduzido em delineamento quadrado latino $5 \times 5$ (cinco suplementos, cinco animais, cinco períodos), em que cada período consistiu em 14 dias, sendo 7 dias para adaptação ao suplemento e 7 dias para coleta das amostras. Diariamente foi mensurado o total de feno, dos suplementos e das sobras, por animal. A determinação do consumo de volumoso e dos suplementos foi por diferença do fornecido e das sobras, corrigidos pela matéria seca.

A degradabilidade do feno de Brachiaria brizantha foi avaliada pela técnica do saco de náilon, conforme Ørskov et al. (1980). Os sacos foram retirados nos tempos 6, 24, 48 e 96 horas após a inserção no rúmen, de acordo com o modelo de Ørskov et al. (1980), ajustado por Sampaio (1997). Foi coletada amostra de líquido ruminal antes do fornecimento da dieta (0 hora), $2,4,6,9,12,18$ e 24 horas, sendo acondicionadas alíquotas de $50 \mathrm{~mL}$ de líquido ruminal de cada amostra em frasco contendo $1 \mathrm{~mL}$ de ácido sulfúrico $1: 1$ e guardadas a $-10^{\circ} \mathrm{C}$ para determinação do nitrogênio amoniacal (N$\mathrm{NH}_{3}$ ).

As análises de matéria seca (MS), matéria mineral (MM), proteína bruta (PB), extrato etéreo $(\mathrm{EE})$, cálcio $(\mathrm{Ca})$ e fósforo $(\mathrm{P})$ foram determinadas conforme AOAC (Association..., 2010). Os teores de fibra em detergente neutro (FDN) e fibra em detergente ácido (FDA) foram analisados conforme o método descrito por Robertson e Van Soest (1981). A análise de lignina Klason, bem como as estimativas de celulose (CEL), hemiceluloses (HCEL) e sílica (SIL) das amostras de volumoso, foi determinada conforme Van Soest et al. (1991). Para determinação dos carboidratos solúveis, foi utilizada a metodologia de Bailey (1967), modificada por Valadares Filho (1981). O N$\mathrm{NH}_{3}$ ruminal foi determinado conforme AOAC (Association..., 2010).

A composição químico-bromatológica dos proteinados e do feno de Braquiaria brizantha cv. Marandu encontra-se na Tabela 2. 
Tabela 2. Composição (\%) dos suplementos proteinados, do feno de Brachiaria brizantha cv. Marandu e das dietas

\begin{tabular}{lcccccc}
\hline \multirow{2}{*}{ Nutrientes } & \multirow{2}{*}{ Feno } & \multicolumn{7}{c}{ Suplementos } \\
\cline { 3 - 7 } & & CSUENC & CSUREIA & MTAMIR & MTURENC & MTUREIA \\
\hline Matéria seca & 89,9 & 88,0 & 91,2 & 90,3 & 91,9 & 89,0 \\
Matéria orgânica & 96,9 & 61,1 & 37,7 & 51,2 & 39,7 & 44,9 \\
Matéria mineral & 3,41 & 38,9 & 62,3 & 48,8 & 60,3 & 55,1 \\
Proteína bruta & 50,5 & 35,4 & 35,8 & 35,3 & 35,2 & 35,5 \\
Proteína degradável no rúmen & - & 31,4 & 31,7 & 30,5 & 30,9 & 30,9 \\
Extrato etéreo & 1,29 & 2,75 & 1,90 & 4,42 & 4,16 & 4,07 \\
Fibra em detergente neutro & 77,1 & 44,9 & 36,9 & 18,8 & 15,3 & 17,4 \\
Fibra em detergente ácido & 49,8 & 15,1 & 10,5 & 1,82 & 1,17 & 1,42 \\
Hemiceluloses & 37,7 & 29,8 & 26,4 & 16,9 & 14,1 & 15,9 \\
Celulose & 27,1 & 31,9 & 26,1 & 6,22 & 4,80 & 6,69 \\
Lignina & 4,90 & - & - & - & - & - \\
Carboidratos solúveis & - & 2,71 & 2,49 & 4,22 & 3,39 & 3,2 \\
Nutrientes digestíveis totais & - & 35,7 & 35,7 & 35,6 & 35,7 & 35,8 \\
Cálcio & 1,26 & 3,85 & 3,85 & 3,71 & 3,66 & 3,66 \\
Fósforo & 3,9 & 2,10 & 2,10 & 2,09 & 2,04 & 2,06 \\
\hline Nutrientes & \multicolumn{7}{c}{ Composição em base da MS da dieta total ${ }^{1}(\%)$} \\
\hline Proteina bruta & 6,94 & 6,95 & 6,89 & 6,90 & 7,11 \\
Nutrientes digestiveis totais & \multicolumn{7}{c}{40,0} & 40,0 & 40,0 & 40,0 & 39,9 \\
Fibra em detergente neutro & \multicolumn{7}{c}{4,8} & 36,9 & 18,7 & 15,3 & 17,4 \\
\hline
\end{tabular}

${ }^{7}$ CSUENC = Casca de soja + Ureia encapsulada; CSUREIA = Casca de soja + ureia; MTAMIR = Milho triturado + amireia; MTURENC $=$ Milho triturado + Ureia encapsulada; MTUREIA $=$ Milho triturado + Ureia. PB $=$ Proteína bruta; NDT $=$ Nutrientes digestíveis totais; FDN $=$ Fibra em detergente neutro. ${ }^{1}$ Valores calculados considerando-se os teores de NDT de 30 a 40\% para o feno de Brachiaria brizantha cv. Marandu, conforme Valadares Filho et al. (2006).

O delineamento experimental foi o quadrado latino $5 \times 5$ (cinco animais, cinco suplementos, cinco períodos). Para o estudo da degradabilidade in situ, os animais foram considerados as parcelas e os tempos de coleta, as subparcelas. A taxa de degradação foi calculada pelo modelo de Ørskov et al. (1980) e ajustada conforme Sampaio (1997). Para calcular a degradabilidade efetiva (DE), foi utilizado o modelo de Ørskov e McDonald (1979). Os resultados de consumo foram analisados através de análise de variância por um modelo linear do PROC GLM do SAS®, versão 9.0. Os coeficientes de degradabilidade in situ foram analisados pelo processo iterativo do algoritmo Marquadt do PROC NLIN do SAS®, versão 9.0. As médias dos tratamentos foram comparadas pelo teste SNK, adotando-se $\alpha$ a $5 \%$ de probabilidade.

\section{RESULTADOS E DISCUSSÃO}

Verificaram-se maiores consumos de proteinado (g de MS/dia) pelos animais submetidos à suplementação contendo MTUREIA, exceto para os animais alimentados com CSUREIA $(\mathrm{P}<0,05)$ (Tab. 3).

Tabela 3. Consumo de matéria seca gramas/dia dos suplementos proteinados

\begin{tabular}{lc}
\hline Tratamento & Matéria seca $(\mathrm{g} / \mathrm{dia})$ \\
\hline Casca de soja + Ureia encapsulada (CSUENC) & $509 \mathrm{~B}$ \\
Casca de soja + Ureia (CSUREIA) & $528 \mathrm{AB}$ \\
Milho triturado + Amireia (MTAMIR) & $510 \mathrm{~B}$ \\
Milho triturado + Ureia encapsulada (MTURENC) & $513 \mathrm{~B}$ \\
Milho triturado + Ureia (MTUREIA) & $555 \mathrm{~A}$ \\
\hline Coeficiente de variação (\%) & 11,9 \\
\hline Médias com letras iguais na coluna não se diferem significativamente pelo teste SNK (P>0,05).
\end{tabular}


Pode-se observar que, embora o fornecimento dos suplementos proteicos tenha sido em $0,08 \%$ do peso vivo, e tendo em vista que os teores de PB dos suplementos foram da ordem de 35,4\% (Tab. 2), notou-se que os teores de PB obtidos na dieta total, considerando-se o efetivamente consumido (Tab. 2), ficaram aquém da recomendação mínima de $7 \%$ de $\mathrm{PB}$ para adequada atividade fermentativa no rúmen (Minson, 1990). Esses aspectos podem implicar um decréscimo no consumo de MS oriunda da forragem. Assim, a resposta animal à suplementação pode variar diretamente pelo nível, bem como, pela qualidade da forragem ofertada ou disponível no pasto e, dessa forma, a finalidade do sal mineral ou do suplemento proteinado é fornecer $\mathrm{N}$ degradável no rúmen, propiciando melhoria no aproveitamento da forragem (Minson, 1990).

A melhoria na eficiência de aproveitamento da forragem ocorre principalmente quando as bactérias fermentadoras de fibras têm adequada disponibilidade de amônia, que é utilizada como principal fonte de N. Em contrapartida, essas bactérias podem ser fortemente prejudicadas quando há deficiência de $\mathrm{N}$ no rúmen, levando a menor desaparecimento da fibra, diminuindo a taxa de passagem e, consequentemente, decréscimo na ingestão de matéria seca (Russell et al., 1992).
Avaliando o desempenho de bovinos de corte a pasto suplementados com misturas múltiplas contendo ureia e amireia, Gonçalves et al. (2004) obtiveram maiores consumos de misturas múltiplas por bovinos no período da seca com ingestões de amireia e ureia de 265 e 246g/animal/dia, respectivamente. Segundo os autores, a maior ingestão da amireia foi atribuída à melhoria na palatabilidade da mistura amido e ureia em decorrência do processo de extrusão. Knorr et al. (2005) pesquisaram o desempenho de novilhos suplementados com sais proteinados em pastagem nativa, e observaram que o tipo de suplemento utilizado afetou o consumo, sendo verificado nos proteinados contendo ureia, amireia, e amireia mais levedura consumos diários médios de 391, 412 e 418g, respectivamente, valores superiores ao obtido pelos animais submetidos somente à suplementação mineral 38g/dia. Os autores evidenciaram ainda que a adição de levedura ativa ao suplemento proteico à base de amireia promoveu maior ganho de peso dos animais em relação à suplementação com sal mineralizado.

Não houve diferenças $(\mathrm{P}>0,05)$ para os consumos de MS (CMS), CMO, CPB e CNDT $\mathrm{kg} / \mathrm{dia}, \%$ do peso vivo (\% PV) e em $\mathrm{g} / \mathrm{kgPV}^{0,75}$, exceto para o CPB $\left(\mathrm{g} / \mathrm{kgPV}^{0,75}\right)$ em que se verificou maior consumo no tratamento CSUENC (Tab. 4).

Tabela 4. Consumo de nutrientes por bovinos alimentados com suplementos proteinados contendo distintas fontes de carboidrato e nitrogênio não proteico

\begin{tabular}{|c|c|c|c|c|c|c|}
\hline \multirow{2}{*}{ Variável $^{\beta}$} & \multicolumn{5}{|c|}{ Tratamento } & \multirow{2}{*}{$\begin{array}{l}\mathrm{CV}^{\mathrm{f}} \\
(\%)\end{array}$} \\
\hline & CSUENC & CSUREIA & MTAMIR & MTURENC & MTUREIA & \\
\hline CMS (kg/dia) & 8,23 & 8,53 & 8,36 & 8,47 & 8,25 & 3,96 \\
\hline CMS $(\% \mathrm{PV})^{1}$ & 1,14 & 1,18 & 1,15 & 1,17 & 1,14 & 4,04 \\
\hline $\mathrm{CMS}\left(\mathrm{g} / \mathrm{kgPV}^{0,75}\right)^{2}$ & 59,1 & 61,4 & 59,9 & 60,8 & 59,4 & 4,02 \\
\hline CMO (kg/dia) & 7,79 & 7,96 & 7,87 & 7,92 & 7,71 & 7,21 \\
\hline $\mathrm{CMO}(\% \mathrm{PV})$ & 1,08 & 1,10 & 1,08 & 1,09 & 1,07 & 7,21 \\
\hline $\mathrm{CMO}\left(\mathrm{g} / \mathrm{kgPV}^{0,75}\right)$ & 55,9 & 57,3 & 56,4 & 56,8 & 55,5 & 7,21 \\
\hline CPB (kg/dia) & 0,571 & 0,594 & 0,577 & 0,583 & 0,586 & 6,76 \\
\hline $\mathrm{CPB}(\% \mathrm{PV})$ & 0,079 & 0,082 & 0,079 & 0,080 & 0,081 & 6,75 \\
\hline $\mathrm{CPB}\left(\mathrm{g} / \mathrm{kgPV}^{0,75}\right)$ & $4,16^{\mathrm{a}}$ & $3,65^{\mathrm{c}}$ & $3,89^{\mathrm{b}}$ & $3,35^{\mathrm{d}}$ & $3,76^{\mathrm{c}}$ & 6,94 \\
\hline CNDT (kg/dia) & 3,29 & 3,41 & 3,34 & 3,39 & 3,30 & 7,09 \\
\hline CNDT (\% PV) & 0,456 & 0,474 & 0,462 & 0,469 & 0,458 & 7,10 \\
\hline CNDT $\left(\mathrm{g} / \mathrm{kgPV}^{0,75}\right)$ & 23,7 & 24,6 & 23,9 & 24,3 & 23,7 & 7,09 \\
\hline
\end{tabular}

${ }^{\beta} \mathrm{CMS}=$ Consumo de matéria seca; $\mathrm{CMO}=$ Consumo de matéria orgânica; $\mathrm{CPB}=$ Consumo de proteína bruta; $\mathrm{CNDT}$ $=$ Consumo de nutrientes digestíveis totais. ${ }^{\ddagger}$ CSUENC $=$ casca de soja + Ureia encapsulada; CSUREIA = casca de soja + ureia; MTAMIR = milho triturado + amireia; MTURENC $=$ milho triturado + Ureia encapsulada; MTUREIA $=$ milho triturado + ureia. ${ }^{1} \% \mathrm{PV}=\%$ do peso vivo. ${ }^{2} \mathrm{~g} / \mathrm{kgPV}^{0,75}=$ gramas $/ \mathrm{kg}$ de peso vivo metabólico. ${ }^{\mathfrak{f}} \mathrm{CV}=$ Coeficiente de variação. As médias não diferiram pelo teste SNK $(\mathrm{P}>0,05)$ entre os tratamentos. ${ }^{a}$ Médias com letras iguais na mesma linha não se diferem significativamente pelo teste $\mathrm{SNK}(\mathrm{P}>0,05)$. 
O consumo médio de MS total $\mathrm{kg} / \mathrm{dia}$ e \% PV foram de 8,37 e 1,15, respectivamente (Tab. 4). Os valores em \% PV foram abaixo do esperado. Conforme avaliações de diversos estudos usados para predição de consumo de MS para bovinos de corte em confinamento, realizadas por Azevêdo et al. (2006) para o sistema BRCORTE, foram observadas ingestões de MS médias por bovinos mestiços de $8,11 \mathrm{~kg} / \mathrm{dia}$ e $2,16 \%$ do PV.

Em alguns estudos sobre condições de alimentação em pasto de Brachiaria brizantha, foram evidenciados consumos de MS médios por bovinos de corte em torno de 2\% PV (Euclides et al., 2000; Gonçalves et al., 2004). Porém, é importante salientar que, em animais em pastejo, dependendo do grau de seleção permitida, há uma ingestão das frações mais digestíveis da forragem, favorecendo maiores consumos. Nesta pesquisa, o manejo alimentar consistiu no fornecimento do volumoso no cocho e, mesmo adotando-se $10 \%$ de sobras do total fornecido, pode ter ocorrido limitação na seleção do feno, implicando menor taxa de passagem da forragem e consequente elevação no tempo de retenção (Minson, 1990). Segundo Coelho da Silva (2011), o consumo fica limitado pela demanda de energia, e não pelo efeito de enchimento do alimento quando a FDN for abaixo de $50 \%$ a $60 \%$. No entanto, o teor de FDN do feno foi $77,1 \%$ (Tab. 2), fato que pode ter provocado limitação física do rúmen (Mertens, 1994), acarretando baixos valores de CMS.

O consumo MO (CMO) é considerado uma resposta que integra os fatores determinantes do consumo e está estreitamente ligado ao consumo de energia metabolizável e ao desempenho dos animais (Cochran et al., 1998). Nesta pesquisa, mesmo não ocorrendo diferenças do CMO pela suplementação com proteinados, essa resposta pode ser consequência do menor CMS, o qual afetou o CMO, fato que ocasionou diminuição da ingestão de energia, com consumos médios de $1,08 \% \mathrm{PV}$ e $56,4 \mathrm{~g} / \mathrm{kgPV}^{0,75}$ de $\mathrm{MO}$ e $0,464 \% \mathrm{PV}$ e $24,0 \mathrm{~g} / \mathrm{kgPV}^{0,75}$ de NDT. Essa baixa ingestão pode estar associada, principalmente, à baixa qualidade do feno, aliada à falta de sincronização da matéria orgânica fermentável em quantidades adequadas com o $\mathrm{N}$ contido nos proteinados.

Para consumo das frações fibrosas, foram obtidos maiores valores de FDN e FDA (kg/dia; $\% \mathrm{PV} ; \mathrm{g} / \mathrm{kgPV}^{0,75}$ ) e HCEL (\% PV; $\mathrm{g} / \mathrm{kgPV}^{0,75}$ ) pelos animais alimentados com CSUREIA em relação àqueles com MTUREIA $(\mathrm{P}<0,05)$. Os suplementos não afetaram o CHCEL (kg/dia) ( $P>0,05)$. Analisando o consumo da fração CEL (CCEL, kg/dia; \% PV; g/kgPV ${ }^{0,75}$ ), evidenciouse que a suplementação com CSUREIA propiciou maiores ingestões em relação a MTAMIR e MTUREIA $(\mathrm{P}<0,05)$, sendo esses consumos similares à MTURENC $(\mathrm{P}>0,05)$ (Tab. 5).

Tabela 5. Consumo das frações fibrosas por bovinos alimentados com suplementos proteinados contendo distintas fontes de carboidrato e nitrogênio não proteico

\begin{tabular}{|c|c|c|c|c|c|c|}
\hline \multirow{2}{*}{ Variável $^{\beta}$} & \multicolumn{5}{|c|}{ Tratamento } & \multirow{2}{*}{$\begin{array}{l}C^{f} \\
(\%)\end{array}$} \\
\hline & CSUENC & CSUREIA & MTAMIR & MTURENC & MTUREIA & \\
\hline CFDN (kg/dia) & $6,18 \mathrm{ab}$ & $6,37 \mathrm{a}$ & $6,14 a b$ & $6,21 \mathrm{ab}$ & $6,04 \mathrm{~b}$ & 7,28 \\
\hline CFDN $(\% \mathrm{PV})^{1}$ & $0,856 \mathrm{ab}$ & $0,884 \mathrm{a}$ & $0,850 \mathrm{ab}$ & $0,860 \mathrm{ab}$ & $0,838 b$ & 7,24 \\
\hline $\mathrm{CFDN}\left(\mathrm{g} / \mathrm{kgPV}^{0,75}\right)^{2}$ & $44,4 \mathrm{ab}$ & $45,8 \mathrm{a}$ & $44,1 \mathrm{ab}$ & $44,6 \mathrm{ab}$ & $43,4 b$ & 7,24 \\
\hline CFDA (kg/dia) & $3,92 \mathrm{ab}$ & $4,04 \mathrm{a}$ & $3,92 \mathrm{ab}$ & $3,97 \mathrm{ab}$ & $3,84 \mathrm{~b}$ & 7,31 \\
\hline CFDA (\% PV) & $0,543 a b$ & $0,561 \mathrm{a}$ & $0,542 \mathrm{ab}$ & $0,550 \mathrm{ab}$ & $0,533 b$ & 7,31 \\
\hline CFDA $\left(\mathrm{g} / \mathrm{kgPV}^{0,75}\right)$ & $28,2 \mathrm{ab}$ & $29,1 \mathrm{a}$ & $28,1 \mathrm{ab}$ & $28,5 \mathrm{ab}$ & $27,6 b$ & 7,31 \\
\hline CHCEL (kg/dia) & 2,25 & 2,30 & 2,23 & 2,25 & 2,18 & 8,44 \\
\hline CHCEL (\% PV) & $0,312 \mathrm{ab}$ & $0,320 \mathrm{a}$ & $0,308 \mathrm{ab}$ & $0,313 \mathrm{ab}$ & $0,302 b$ & 8,31 \\
\hline CHCEL $\left(\mathrm{g} / \mathrm{kgPV}^{0,75}\right)$ & $16,2 \mathrm{ab}$ & $16,6 \mathrm{a}$ & $15,9 \mathrm{ab}$ & $16,2 \mathrm{ab}$ & $15,6 \mathrm{~b}$ & 8,28 \\
\hline CCEL (kg/dia) & $2,25 \mathrm{ab}$ & $2,28 \mathrm{a}$ & $2,16 b c$ & $2,19 \mathrm{abc}$ & $2,12 \mathrm{c}$ & 8,50 \\
\hline CCEL (\% PV) & $0,312 \mathrm{ab}$ & $0,318 \mathrm{a}$ & $0,298 b c$ & $0,304 a b c$ & $0,293 \mathrm{c}$ & 8,39 \\
\hline $\operatorname{CCEL}\left(\mathrm{g} / \mathrm{kgPV}^{0,75}\right)$ & $16,2 \mathrm{ab}$ & $16,5 \mathrm{a}$ & $15,5 \mathrm{bc}$ & $15,8 \mathrm{abc}$ & $15,2 \mathrm{c}$ & 8,34 \\
\hline
\end{tabular}

${ }^{\beta}$ CFDN = Consumo de fibra em detergente neutro; CFDA = Consumo de fibra em detergente ácido; CHCEL = Consumo de hemiceluloses; $\mathrm{CCEL}=$ Consumo de celulose. ${ }^{¥}$ CSUENC = casca de soja + Ureia encapsulada; CSUREIA $=$ casca de soja + ureia MTAMIR $=$ milho triturado + amireia $;$ MTURENC $=$ milho triturado + Ureia encapsulada, MTUREIA = milho triturado + ureia. ${ }^{1}$ Porcentagem do peso vivo. ${ }^{2} \mathrm{Gramas} / \mathrm{kg}$ de peso vivo ${ }^{0,75} .{ }^{£} \mathrm{CV}=$ Coeficiente de variação. ${ }^{a}$ Médias com letras iguais na mesma linha não se diferem significativamente pelo teste SNK $(\mathrm{P}>0,05)$. 
Os maiores consumos das frações fibrosas observados nos tratamentos que continham ureia encapsulada ou ureia comum, quando estas foram associadas com casca de soja como fonte de carboidrato, foram fortemente influenciados pelos teores de FDN 44,9 e 36,9\%, respectivamente (Tab. 2). Já os suplementos constituídos por milho como fonte de carboidrato apresentaram média de FDN 17,2 \% (Tab. 2). É importante salientar que a quantidade de amônia incorporada na proteína microbiana é dependente da concentração de energia fermentável da dieta, sendo os carboidratos os principais fornecedores de energia e de esqueleto de carbono que podem possibilitar essa síntese proteica.

Os tratamentos constituídos pelos diferentes proteinados não afetaram a degradabilidade in situ das frações MS, MO, PB, FDN, FDA, HCEL $(\mathrm{P}>0,05)$, exceto para a fração potencialmente degradável da celulose, em que se verificou superioridade para o CSUREIA e MTURENC em comparação ao tratamento MTUREIA $(\mathrm{P}<0,05)($ Tab. 6, 7, 8).

Tabela 6. Degradação ruminal da matéria seca, matéria orgânica e proteína bruta do Brachiaria brizantha cv. Marandu

\begin{tabular}{|c|c|c|c|c|c|c|c|}
\hline \multirow{3}{*}{ Tratamento } & \multicolumn{7}{|c|}{ Matéria Seca } \\
\hline & \multirow{2}{*}{$\mathrm{S}(\%)$} & \multirow{2}{*}{ B1 $(\%)$} & \multirow{2}{*}{$\mathrm{DP}(\%)$} & \multirow{2}{*}{$\mathrm{c}(/ \mathrm{h})$} & \multirow{2}{*}{$\mathrm{R}^{2}$} & \multicolumn{2}{|c|}{$\mathrm{DE}(\%)$} \\
\hline & & & & & & $0,02 / \mathrm{h}$ & $0,05 / \mathrm{h}$ \\
\hline CSUENC & 14,2 & 62,1 & 76,3 & 0,030 & 99,9 & 51,5 & 37,5 \\
\hline CSUREIA & 14,3 & 62,5 & 76,0 & 0,032 & 99,9 & 52,8 & 38,7 \\
\hline MTAMIR & 15,1 & 59,3 & 74,4 & 0,032 & 99,9 & 52,0 & 38,7 \\
\hline MTURENC & 14,9 & 62,8 & 77,7 & 0,030 & 99,9 & 62,8 & 39,4 \\
\hline \multirow[t]{2}{*}{ MTUREIA } & 15,9 & 61,8 & 77,6 & 0,028 & 99,1 & 61,8 & 38,0 \\
\hline & \multicolumn{7}{|c|}{ Matéria Orgânica } \\
\hline CSUENC & 3,83 & 71,1 & 74,9 & 0,030 & 99,6 & 46,5 & 30,5 \\
\hline CSUREIA & 2,85 & 71,0 & 73,3 & 0,032 & 99,9 & 47,1 & 31,1 \\
\hline MTAMIR & 5,32 & 67,2 & 72,5 & 0,032 & 99,8 & 46,7 & 31,5 \\
\hline MTURENC & 5,02 & 71,2 & 76,2 & 0,030 & 99,7 & 48,3 & 32,3 \\
\hline \multirow[t]{2}{*}{ MTUREIA } & 6,34 & 69,4 & 75,8 & 0,028 & 99,8 & 46,8 & 31,3 \\
\hline & \multicolumn{7}{|c|}{ Proteína Bruta } \\
\hline CSUENC & 30,6 & 35,3 & 65,9 & 0,041 & 97,9 & 52,3 & 44,3 \\
\hline CSUREIA & 32,6 & 40,3 & 71,1 & 0,039 & 98,5 & 56,1 & 47,1 \\
\hline MTAMIR & 32,2 & 41,6 & 64,5 & 0,050 & 98,6 & 57,8 & 48,5 \\
\hline MTURENC & 30,6 & 43,3 & 73,9 & 0,043 & 99,1 & 58,4 & 48,7 \\
\hline MTUREIA & 34,6 & 44,9 & 67,9 & 0,033 & 98,3 & 58,1 & 48,3 \\
\hline
\end{tabular}

CSUENC $=$ casca de soja + Ureia encapsulada; CSUREIA = casca de soja + ureia; MTAMIR $=$ milho triturado + amireia; MTURENC = milho triturado + Ureia encapsulada; MTUREIA = milho triturado + ureia; $\mathrm{S}=$ Fração solúvel (\%); B1 = Potencialmente degradável $(\%) ; \mathrm{DP}=$ Degradabilidade potencial $\left(\mathrm{h}^{1}\right) ; \mathrm{DE}=$ Degradação efetiva $\left(\% / \mathrm{h}^{1}\right) ; \mathrm{c}$ $=$ Taxa de degradação $\left(\mathrm{h}^{1}\right) ; \mathrm{R}^{2}=$ Coeficiente de determinação. As médias não se diferiram pelo teste $\mathrm{SNK}(\mathrm{P}>0,05)$ entre os tratamentos.

Faulkner et al. (1994) não observaram diferenças na digestibilidade da MS no trato total de novilhos suplementados com milho ou casca de soja. O amido do milho e a pectina da casca de soja são fontes de carboidratos que possuem disponibilidade ruminal semelhantes (Sniffen et al., 1992). Neste estudo, não foram observadas diferenças na digestibilidade da forragem entre os suplementos à base de milho ou casca de soja. Dessa forma, a substituição do milho pela casca de soja na formulação de proteinados apresentase como importante alternativa, desde que, no momento da aquisição, sejam considerados aspectos como disponibilidade e preços competitivos em relação ao milho.

Os valores médios de degradabilidade potencial para as frações HCEL e CEL foram 70,9 e $67,8 \%$, respectivamente (Tab. 8). 
Tabela 7. Degradação ruminal da fibra em detergente neutro e fibra em detergente ácido do Brachiaria brizantha cv. Marandu

\begin{tabular}{|c|c|c|c|c|c|c|c|}
\hline \multirow{3}{*}{ Tratamento } & \multicolumn{7}{|c|}{ Fibra em detergente neutro } \\
\hline & \multirow{2}{*}{ S (\%) } & \multirow{2}{*}{ B1 (\%) } & \multirow{2}{*}{ DP (\%) } & \multirow{2}{*}{$\mathrm{c}(/ \mathrm{h})$} & \multirow{2}{*}{$\mathrm{R}^{2}$} & \multicolumn{2}{|c|}{$\mathrm{DE}(\%)$} \\
\hline & & & & & & $0,02 / \mathrm{h}$ & $0,05 / \mathrm{h}$ \\
\hline CSUENC & 14,2 & 64,4 & 78,9 & 0,030 & 99,9 & 53,2 & 38,7 \\
\hline CSUREIA & 15,7 & 54,8 & 71,7 & 0,046 & 97,7 & 53,6 & 41,6 \\
\hline MTAMIR & 14,6 & 62,7 & 77,3 & 0,034 & 99,8 & 54,0 & 39,9 \\
\hline MTURENC & 14,9 & 65,9 & 80,9 & 0,030 & 99,8 & 55,1 & 40,2 \\
\hline \multirow[t]{2}{*}{ MTUREIA } & 14,4 & 66,5 & 80,9 & 0,028 & 99,8 & 53,8 & 38,8 \\
\hline & \multicolumn{7}{|c|}{ Fibra em detergente ácido } \\
\hline CSUENC & 14,5 & 67,9 & 66,0 & 0,029 & 94,1 & 46,7 & 28,1 \\
\hline CSUREIA & 15,9 & 58,5 & 68,3 & 0,045 & 94,2 & 43,6 & 29,4 \\
\hline MTAMIR & 14,9 & 67,1 & 68,3 & 0,031 & 97,3 & 46,7 & 29,1 \\
\hline MTURENC & 14,4 & 74,4 & 66,2 & 0,025 & 96,8 & 49,6 & 28,1 \\
\hline MTUREIA & 13,7 & 72,5 & 66,4 & 0,027 & 97,0 & 48,0 & 27,6 \\
\hline
\end{tabular}

$¥$ CSUENC $=$ casca de soja + ureia encapsulada; CSUREIA $=$ casca de soja + ureia; MTAMIR = milho triturado + amireia; MTURENC = milho triturado + ureia encapsulada; MTUREIA = milho triturado + ureia; $\mathrm{S}=$ Fração solúvel $(\%) ; \mathrm{B} 1=$ Potencialmente degradável $(\%) ; \mathrm{DP}=$ Degradabilidade potencial $\left(\mathrm{h}^{1}\right) ; \mathrm{DE}=$ Degradação efetiva $\left(\% / \mathrm{h}^{1}\right) ; \mathrm{c}$ $=$ Taxa de degradação $\left(\mathrm{h}^{1}\right) ; \mathrm{R}^{2}=$ Coeficiente de determinação. As médias não se diferiram pelo teste $\mathrm{SNK}(\mathrm{P}>0,05)$ entre os tratamentos. *As médias não se diferiram pelo teste SNK $(\mathrm{P}=0,051)$ entre os tratamentos. ${ }^{\mathrm{a}}$ Médias com letras iguais na mesma linha não se diferem significativamente pelo teste $\mathrm{SNK}(\mathrm{P}>0,05)$.

Tabela 8. Degradação ruminal da hemicelulose e celulose do Brachiaria brizantha cv. Marandu

\begin{tabular}{|c|c|c|c|c|c|c|c|}
\hline \multirow{3}{*}{ Tratamento } & \multicolumn{7}{|c|}{ Hemicelulose } \\
\hline & \multirow{2}{*}{$\mathrm{S}(\%)$} & \multirow{2}{*}{ B1 $(\%)$} & \multirow{2}{*}{$\mathrm{DP}(\%)$} & \multirow{2}{*}{$\mathrm{c}(/ \mathrm{h})$} & \multirow{2}{*}{$\mathrm{R}^{2}$} & \multicolumn{2}{|c|}{$\mathrm{DE}(\%)$} \\
\hline & & & & & & $0,02 / \mathrm{h}$ & $0,05 / \mathrm{h}$ \\
\hline CSUENC & 14,7 & 58,1 & 72,9 & 0,034 & 99,8 & 50,9 & 37,8 \\
\hline CSUREIA & 15,3 & 47,9 & 64,2 & 0,035 & 97,7 & 50,1 & 39,9 \\
\hline MTAMIR & 13,9 & 56,1 & 70,0 & 0,040 & 99,7 & 50,7 & 38,1 \\
\hline MTURENC & 16,1 & 58,6 & 74,6 & 0,034 & 99,7 & 43,5 & 43,3 \\
\hline \multirow[t]{2}{*}{ MTUREIA } & 15,8 & 57,2 & 73,1 & 0,033 & 99,5 & 40,8 & 40,9 \\
\hline & \multicolumn{7}{|c|}{ Celulose } \\
\hline CSUENC & 17,2 & $50,2^{\mathrm{ab}}$ & 67,3 & 0,031 & 97,2 & 47,2 & 35,9 \\
\hline CSUREIA & 16,4 & $53,3^{\mathrm{a}}$ & 69,7 & 0,048 & 93,1 & 48,4 & 36,3 \\
\hline MTAMIR & 17,1 & $48,3^{\mathrm{ab}}$ & 65,4 & 0,032 & 94,7 & 46,1 & 35,2 \\
\hline MTURENC & 21,4 & $52,8^{\mathrm{a}}$ & 67,9 & 0,031 & 97,2 & 46,8 & 34,9 \\
\hline MTUREIA & 27,9 & $44,7^{\mathrm{b}}$ & 68,7 & 0,026 & 95,0 & 50,9 & 40,8 \\
\hline
\end{tabular}

CSUENC $=$ casca de soja + ureia encapsulada; CSUREIA = casca de soja + ureia; MTAMIR = milho triturado + amireia; MTURENC = milho triturado + ureia encapsulada; MTUREIA = milho triturado + ureia; $\mathrm{S}=$ Fração solúvel $(\%) ; \mathrm{B} 1=$ Potencialmente degradável $(\%) ; \mathrm{DP}=$ Degradabilidade potencial $\left(\% / \mathrm{h}^{1}\right) ; \mathrm{DE}=$ Degradação efetiva $\left(\% / \mathrm{h}^{1}\right)$; $\mathrm{c}=$ Taxa de degradação $\left(\mathrm{h}^{1}\right) ; \mathrm{R}^{2}=$ Coeficiente de determinação. As médias não se diferiram pelo teste $\mathrm{SNK}(\mathrm{P}>0,05)$ entre os tratamentos. *As médias não se diferiram pelo teste SNK ( $\mathrm{P}=0,051)$ entre os tratamentos. ${ }^{\mathrm{a}}$ Médias com letras iguais na mesma linha não se diferem significativamente pelo teste $\mathrm{SNK}(\mathrm{P}>0,05)$.

Considerando-se que a composição dessas frações no feno foi de aproximadamente $27 \%$, a maior degradabilidade obtida para HCEL pode estar associada ao baixo teor de lignina do feno de $B$. brizantha (Tab. 2), visto que a interação da lignina com a hemicelulose em gramíneas, mediante ligações com os carboidratos estruturais, pode implicar inibição da digestão. A digestibilidade da HCEL possui relação direta com a concentração de CEL e inversamente, com a taxa de lignificação, uma vez que a HCEL pode associar-se de forma mais complexa com a lignina (Van Soest, 1994).

A concentração de $\mathrm{N}-\mathrm{NH}_{3}$ no líquido ruminal foi influenciada pela composição dos proteinados $(\mathrm{P}<0,05)$, sendo superior para os tratamentos MTUREIA e MTURENC em relação ao CSURENC, sendo estes semelhantes aos demais (Tab. 9). Observou-se que os picos de $\mathrm{N}-\mathrm{NH}_{3}$ foram obtidos nos tempos 2 e 4 h após pósprandial $(\mathrm{P}<0,05)$. 
Tabela 9. Concentrações de nitrogênio amonial (mg/dL) no líquido ruminal de bovinos suplementados com distintas fontes de carboidrato e nitrogênio não proteico

\begin{tabular}{ccccccc}
\hline \multirow{2}{*}{ Horário } & \multicolumn{5}{c}{ Tratamento } & \multirow{2}{*}{ Médias } \\
\cline { 2 - 5 } & CSUENC & CSUREIA & MTAMIR & MTURENC & MTUREIA & \\
\hline 0 & 1,88 & 2,10 & 2,45 & 2,30 & 1,96 & $2,14 \mathrm{C}$ \\
2 & 8,47 & 9,29 & 8,84 & 11,0 & 13,3 & $10,2 \mathrm{~A}$ \\
4 & 7,18 & 10,0 & 9,38 & 9,96 & 12,2 & $9,75 \mathrm{~A}$ \\
6 & 5,52 & 7,64 & 7,20 & 7,42 & 8,23 & $7,20 \mathrm{~B}$ \\
9 & 2,74 & 2,54 & 4,19 & 4,32 & 3,70 & $3,50 \mathrm{C}$ \\
12 & 2,18 & 1,04 & 4,36 & 4,85 & 1,77 & $2,84 \mathrm{C}$ \\
18 & 1,06 & 1,10 & 1,34 & 1,28 & 1,52 & $1,26 \mathrm{D}$ \\
24 & 2,80 & 2,66 & 2,30 & 2,83 & 3,69 & $2,88 \mathrm{C}$ \\
\hline Médias & $3,98 \mathrm{~b}$ & $4,55 \mathrm{ab}$ & $5,02 \mathrm{ab}$ & $5,50 \mathrm{a}$ & $5,80 \mathrm{a}$ & \\
\hline
\end{tabular}

${ }^{¥}$ CSUENC $=$ casca de soja + ureia encapsulada; CSUREIA $=$ casca de soja + ureia; MTAMIR $=$ milho triturado +

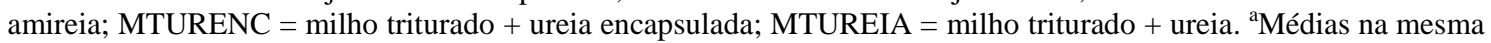
linha seguidas de letras iguais não se diferem pelo teste $t(P>0,05)$. ${ }^{A}$ Médias na mesma coluna seguidas de letras iguais não se diferem pelo teste Student-Newman-Keuls $(\mathrm{P}>0,05)$.

A taxa de degradação ruminal da fonte energética é o principal fator limitante para utilização de NNP, e a rápida degradação da ureia no rúmen pode acarretar em aumento nas concentrações de $\mathrm{N}_{-} \mathrm{NH}_{3}$. Além disso, pode ocorrer alta absorção de amônia pela parede ruminal, se os carboidratos fermentáveis não são suficientes no rúmen. A menor concentração de $\mathrm{N}-\mathrm{NH}_{3}$ no CSUENC, quando comparados a MTURENC e MTUREIA, pode ser indicativo de melhor sincronia entre a liberação do $\mathrm{N}$ da ureia encapsulada e a degradação da pectina, principal carboidrato da casca de soja, propiciando imediata utilização da amônia liberada pelos microrganismos ruminais. Stiles et al. (1975) sugerem que as menores concentrações de amônia observadas na suplementação com amireia, em relação à ureia, podem ser decorrentes do processamento do grão e não da liberação mais lenta do N. Os níveis de amônia no líquido ruminal variaram consideravelmente em todas as dietas, sendo que, a partir de nove horas após a alimentação, mantiveram-se abaixo do valor de $5 \mathrm{mg} / \mathrm{dL}$, apontado por Satter e Slyter (1974) como nível crítico para permitir máximo crescimento microbiano.

\section{CONCLUSÕES}

As combinações entre diferentes fontes de nitrogênio não proteico e de carboidratos nos diferentes suplementos não modificam o consumo e a degradabilidade da forragem. Dessa forma, a escolha dos ingredientes para formulação de proteinados deve ser realizada considerando disponibilidade e preço desses suplementos.

\section{REFERÊNCIAS}

ASSOCIATION of official analytical chemists AOAC. Official Methods of Analysis. 18.ed. Maryland: USA, 2010. 3000p.

AZEVÊDO, J.A.G.; VALADARES FILHO, S.C.; PINA, D.S. et al. Predição de consumo de matéria seca por bovinos de corte em confinamento. In: VALADARES FILHO, S.C. et al. (Eds). Exigências Nutricionais de Zebuínos Puros e Cruzados 2 - BRCORTE. Viçosa: Editora Viçosa, 2006. p.1-12.

COCHRAN, R.C.; KOSTER, H.H.; OLSON, K.C. et al. Supplemental protein sources for grazing beef cattle. In: ANNUAL FLORIDA RUMINANT NUTRITION SYMPOSIUM, 9., 1998, Gainesville. Proceedings... Gainesville: [s.n.] 1998. p.123-136.

COELHO DA SILVA, J.F. Mecanismos reguladores de consumo. In: BERCHIELLI, T.T.; PIRES, A.V.; OLIVEIRA, S.G. (Eds.) Nutrição de Ruminantes. 2.ed. Jaboticabal: Funep, 2011. p.61-81.

EUCLIDES, V.P.B.; CARDOSO, E.G.; MACEDO, M.C.M. et al. Consumo voluntário de Brachiaria decumbens cv. Basilisk e Brachiaria brizantha cv. Marandu sob pastejo. Rev. Bras. Zootec., v.6, p.22002208, 2000. (Suplemento 2).

FAULKNER, D.B.; HUMMEL, D.F.; BUSKIRK, D.D. et al. Performance and nutrient metabolism by nursing calves with limited or unlimited corn or soyhulls. J. Anim. Sci, v.2, p.470-477, 1994.

GONÇALVES, C.C.M.; TEIXEIRA, J.C.; EVANGELISTA, A.R. Desempenho de bovinos de corte no pasto suplementados com misturas múltiplas contendo ureia e amireia. Cienc. Agrotec., v.28, p.174181,2004 
KNORR, M.; PATINO, H.O.; SILVEIRA, A.L.F. et al. Desempenho de novilhos suplementados com sais proteinados em pastagem nativa. Pesq. Agropec. Bras., v.8, p.783-788, 2005.

MERTENS, D.R. Regulation of forage intake. In: FAHEY JR., G.C. (Ed.). Forage quality, evaluation, and utilization. Madison: ASA, 1994. p.450-493.

MINSON, D.J. (Ed). Forage in ruminant nutrition. San Diego: Academic Press, 1990. 483p.

OLIVEIRA, L.O.F; SALIBA, E.O.S.; GONÇALVES, L.C. et al. Digestibilidade in situ e cinética ruminal de bovinos de corte a pasto sob suplementação com proteinados. Rev. Bras. Zootec., v.6, p.1328-1335, 2010.

ØRSKOV, E.R.; HOVELL, F.D.; MOULD, F. The use of the nylon bag technique for evaluation of feedstuffs. Trop. Anim. Prod., v.5, p.195-21, 1980.

ØRSKOV, E.R.; McDONALD, I. The estimation of protein degradability in the rumen from incubation measurements weighed according to rate of passage. $J$. Agric. Sci., v.92, p.499-503, 1979.

PEREIRA, L.G.R.; ANTUNES, R.C.; GONÇALVES, L.C. et al. O milho na alimentação de gado de leite. In: GONÇALVES, L.C.; BORGES, I.; FERREIRA, P.D.S. (Eds.). Alimentos para gado de leite. (Eds). Belo Horizonte: FEPMVZ, 2009. p.240-269.

ROBERTSON, J.B.; VAN SOEST, P.J. The detergent system of analysis and its application to human foods. In: JAMES, W.P.T.; THEANDER, O. (Eds.). The analysis of dietary fiber in food. New York: Marcel Dekker, 1981. p.123-158.

RUSSELL, J.B.; O'CONNOR, J.D; FOX, D.G. et al. A net carbohydrate and protein system for evaluating cattle diets: I. Ruminal fermentation. J. Anim. Sci., v.11, p.3551-3561, 1992.

SAMPAIO, I.B.M. Métodos estatísticos aplicados à determinação de digestibilidade in situ In: SIMPÓSIO INTERNACIONAL DE DIGESTIBILIDADE EM RUMINANTES, Lavras, 1997. Anais... Lavras: UFLA, [s.n.] 1997. p.165-178.
SAS Institute Inc. SAS® User Guide: Statitics. Version 5 edition. Cary, NC:SAS Institute Inc., 1985. 956p.

SATTER, L.D.; SLYTER, L.L. Effect of ammonia concentration on rumen microbial protein production in vitro. Br. J. Nutr., v.32, p.199. 1974.

SNIFFEN, C.J.; O'CONNOR, J.D.; VAN SOEST, P.J. et al. A net carbohydrate and protein system for evaluation cattle diets: II. Carbohydrates and protein availability. J. Anim. Sci., v.10, p.3562-3577, 1992.

STILES, D.A.; LEE, D.D.; BARTLEY, E.E. Starea, soybean meal and urea as nitrogen sources for lactating cows. J. Dairy Sci., v.58, p.777-778, 1975.

TEDESCHI, L.O; BAKER, J.; KETCHEN, D.J. et al. Performance of growing and finishing cattle supplemented with a slow-release urea product and urea. Can. J. Anim. Sci., v.4, p.567-573, 2002.

THIAGO, L.R.L.S. Suplementação de bovinos em pastejo. In: CURSO SOBRE SUPLEMENTAÇÃO MINERAL EM BOVINOS. Campo Grande: EMBRAPA-CNPGC, 1998. p.50-69.

VALADARES FILHO, S.C. Digestibilidade aparente $e$ locais de digestão da matéria seca, energia $e$ carboidratos de fenos de soja perene. 1981. 88f. Dissertação (Mestrado em Zootecnia) - Escola de Veterinária, Universidade Federal de Minas Gerais, Belo Horizonte.

VALADARES FILHO, S.C.; MAGALHÃES, K.A.; ROCHA JUNIOR, V.R. et al. (Ed). Tabelas brasileiras de composição de alimentos para bovinos. CQBAL 2.0. 2.ed. Viçosa: Suprema Gráfica Ltda. 2006. 329p.

VAN SOEST, P.J. Nutritional ecology of the ruminant. Ithaca: Comstock Publ. Assoc. 1994. 476p.

VAN SOEST, P.J.; ROBERTSON, J.B.; LEWIS, B.A. Methods for dietary fiber, neutral detergent fiber, and non starch polysaccharides in relation to animal nutrition. J. Dairy Sci., v.74, p.3583-3597, 1991. 